\title{
Al rescate de Sor Juana Inés de la Cruz: Luisa Luisi en Contemporáneos"
}

\author{
Mariana Moraes Medina*
}

Recibido el 27 de junio de 2019; aceptado el 13 de septiembre de 2019

\section{RESUMEN}

La publicación de un ensayo de la poeta y crítica uruguaya Luisa Luisi en la revista Contemporáneos ha sido referida como uno de los resultados concretos de la diplomacia cultural del México posrevolucionario en el Río de la Plata. No obstante, el texto en sí mismo — una mirada apasionada a la trayectoria biográfica e intelectual de Sor Juana Inés de la Cruz y una impugnación de las lecturas masculinas en torno a su obra- no ha recibido hasta el momento la atención de la crítica literaria. El objetivo de este artículo es analizar el ensayo en cuestión a la luz de la trayectoria intelectual y biográfica de Luisi, procurando dar cuenta de las estrategias de apropiación desarrolladas por la autora en torno de la figura de Sor Juana. En esta operación discursiva figuran las tensiones relativas a la legitimación de las mujeres en el espacio escritural, en particular, en el de la crítica literaria, como terreno racional del sistema literario reservado al varón. Este trabajo podría representar un aporte al estudio de la recepción de Sor Juana Inés de la Cruz en el Río de la Plata, así como a la profundización en la obra de Luisa Luisi.

Palabras clave: Luisa Luisi, Sor Juana Inés de la Cruz, revista Contemporáneos, crítica literaria, recepción literaria.

* El presente trabajo es resultado de la estancia de investigación como becaria del Programa de Becas Posdoctorales de la Universidad Nacional Autónoma de México (UNAM), México, realizada en el Centro de Investigaciones sobre América Latina y el Caribe (CIALC), con la asesoría de la doctora Regina Crespo.

** UNAM, México. Correo electrónico: mmoraes.medina@gmail.com.

ORCID: 0003-2826-5580. 


\title{
To the rescue of Sor Juana Inés de la Cruz: Luisa Luisi in Contemporáneos
}

\begin{abstract}
The publication of an essay by the Uruguayan poet and critic Luisa Luisi in the Contemporáneos journal has been referred to as one of the concrete results of post-revolutionary Mexico's cultural diplomacy in the Río de la Plata. However, Luisi's text itself — a passionate look at Juana Ines de la Cruz' biographical and intellectual career and a rebuttal of the masculine readings of her work - has not received the attention of literary criticism. The objective of this article is to analyze the above mentioned essay in the light of Luisi's intellectual and biographical career, trying to account for her strategies of appropriation developed around the figure of Sor Juana. In this discursive operation, tensions regarding to the legitimization of women in the scriptural space are perceiveid, in particular, in that of literary criticism, as the literary system's rational terrain reserved for men. This article could represent a contribution to the study of Sor Juana Ines de la Cruz' reception in Rio de la Plata, as well as to furthering the study of Luisa Luisi's work.

Key words: Luisa Luisi, Sor Juana Inés de la Cruz, Contemporáneos journal, literary criticism, literary reception.
\end{abstract}

A

principios de 1929, la revista Contemporáneos (número 9, febrero 1929), publicaba el ensayo “Sor Juana Inés de la Cruz”. El asunto del texto —la "Décima Musa" - no era para nada ajeno al grupo de poetas y críticos que nucleaba la publicación, no obstante, sí lo era la firma al pie del ensayo. La misma, pertenecía a Luisa Luisi, figura escasamente conocida en el ámbito mexicano y una de las pocas mujeres que verían una colaboración suya en la revista.

En el presente artículo examinamos la colaboración de Luisi en Contemporáneos procurando dar cuenta de la recepción de Sor Juana propuesta por la escritora uruguaya. A estos efectos, proponemos: 1) un repaso de la trayectoria intelectual y vital de Luisi con la finalidad de dejar asentadas ciertas claves que ayuden a dar cuenta de su acercamiento crítico a la escritora novohispana; 2) las condiciones sociales y culturales que rodearon la escritura y publicación de su ensayo en Contemporáneos y 3) el análisis de la apropiación de Sor Juana propuesta por la escritora uruguaya a la luz de ciertos aportes teóricos de la crítica feminista. Las fuentes primarias empleadas en este trabajo se componen —aparte del mencionado ensayo- de textos 
críticos y poéticos de Luisi. Proponemos como hipótesis de lectura que la apropiación de Sor Juana Inés de la Cruz construida por Luisi, al presentarse como un rescate de la escritora novohispana de la interpretación hegemónica por parte de la crítica literaria desarrollada por los varones, se inscribe en la lucha secular por la legitimación del ejercicio interpretativo por parte de las mujeres y guarda relación con la propia inscripción de Luisi en el campo literario uruguayo de la época.

\section{LUISA LUISI: ENTRE INTERDICCIONES Y TRANSGRESIONES}

La suerte crítica de la escritora Luisa Luisi (1883-1940) ha transcurrido mayormente en la vereda del olvido, como lo ha señalado una temprana e ineludible valoración de Ida Vitale. ${ }^{1}$ Incluso en la propia memoria cultural uruguaya su presencia se inscribe con bordes difuminados. Consecuencia de ello es la muy frecuente confusión de la autora con alguna de sus también aventajadas hermanas. ${ }^{2}$

Aparte de una destacada animadora del campo cultural uruguayo de los veinte (poeta, colaboradora en numerosas publicaciones, conferencista), Luisi sumó a su órbita de actividades la militancia política (en un sector socialista del Partido Colorado) y se desempeñó, durante varios períodos, en cargos públicos que acrecentaron su notoriedad y le aseguraron algunas inquinas. ${ }^{3}$ Su nombre figura como un nodo en diversas redes continentales, destacando especialmente los intercambios con figuras como Alfonso Reyes

1 Vitale, Los poetas del Veinte, p. 331.

2 Paulina, Ana, Luisa, Clotilde, Inés y Elena Luisi conformaron un colectivo emblemático de la conquista de los derechos de las mujeres en el Uruguay de principios de siglo XX. Hijas de inmigrantes europeos con ideas liberales (padre italiano, masón; madre francesa, educada en la Sorbona), las Luisi supieron abrirse un lugar en circuitos reservados a los varones: los estudios universitarios, el periodismo, la política y cargos directivos, entre otros. Cfr. López, El legado de las hermanas Luisi. Paulina Luisi fue la primera doctora en Medicina y Cirugía del Uruguay (1909) y una de las pioneras del feminismo en el país. Clotilde Luisi, por su parte, la primera Doctora en Derecho (1911), catedrática de la misma facultad y directora de la Universidad de Mujeres. La desidia y el desinterés por la memoria de Luisa se han traducido en el hecho de que no exista un archivo de consulta pública que permita estudiar a la autora con mayor detalle (como sí los hay para Paulina y Clotilde Luisi).

3 El caso de Luisi se asimila al de otros tantos escritores uruguayos del período cercanos al poder (entre ellos, Oribe, Sabat Ercasty o Zum Felde). La prolongada permanencia del Batllismo - facción del Partido Colorado- en el gobierno le permitió extender su hegemonía sobre el campo intelectual, en una suerte de cooptación que hizo que muchos creadores y críticos gozaran de protección por parte del Estado. Cfr. Achugar, "La década del veinte. Vanguardia y batllismo. El intelectual y el Estado”. 
y Gabriela Mistral, quien afirmó: "Luisa Luisi fue mucho más para mí que una escritora amiga, fue una de las fuerzas espirituales de la América”. ${ }^{4}$

Su trayectoria intelectual representa de forma ejemplar las conquistas y las resistencias que debieron enfrentar las mujeres en su profesionalización e ingreso al campo letrado. Nuestra autora se graduó como maestra en 1903, en el Instituto Normal de Señoritas de Montevideo. Ocupó luego la cátedra de lectura y declamación en ese mismo instituto, y de Lengua Castellana en Enseñanza Secundaria hasta su jubilación, en 1929. Fue delegada uruguaya en los congresos americanos del niño y miembro del Consejo de Educación Primaria. Como otras escritoras-maestras del período, Luisi pudo saltar (no sin dificultades) la brecha que separaba a la cultura magisterial de la cultura letrada, un coto cerrado bajo el dominio de los varones y con escasas representantes mujeres.

Para el acercamiento entre esos mundos distantes y que representaban el mapa de lo permitido y lo prohibido para una mujer, el ejercicio del periodismo fue una vía sumamente útil. Al cumplirse el décimo aniversario de la muerte de Luisa Luisi, el escritor y crítico Vicente Salaverri dio forma a una semblanza que interesa repasar a estos efectos. La anécdota más interesante evoca la audacia de la autora al presentarse a trabajar en la redacción del periódico La Razón, hecho ante el que Salaverri recalca que su diploma "era apenas de maestra". ${ }^{5}$ La entrada de Luisi a aquel coto varonil representó para el plantel de cronistas toda una novedad y alteró sus hábitos, pues el periódico había tenido colaboradoras muy distinguidas pero "que escribían en sus casas y mandaban sus escritos". ${ }^{6}$ Otra particularidad del comportamiento de la autora es que si bien había sido contratada para cubrir todo lo referente a la información escolar (que era un campo de intereses permitidos a una mujer, por ser la escuela el espacio de continuación de la domesticidad), ella se permitía "someterle al director cuantos sueltos se le ocurriera escribir sobre otra materia". ${ }^{7}$

Con el tiempo Luisi abandonó el diario y se concentró en la docencia y la literatura. Publicó cuatro libros de poemas, enmarcados en el posmodernismo literario, Sentir (1916), Inquietud (1921), Poemas de la inmovilidad, Canciones al sol (1926) y Polvo de días (1935). En el canon vigente por entonces las maestras-escritoras practicaban mayormente dos géneros "permitidos": los libros de lectura y la poesía. Mientras que los primeros se concebían como cercanos a su ejercicio profesional, porque eran herramientas

\footnotetext{
Mistral, "Mensaje sobre Luisa Luisi”, s/p.

Salaverri, "Presencia de Luisa Luisi”, p. 230.

Ídem.

Ídem.
} 
de alfabetización imprescindibles (no sólo ayudaban a enseñar a leer y escribir, sino que servían para inculcar valores morales y patrióticos), los segundos eran percibidos como un reflejo de la subjetividad y las emociones, como una expresión propia de la naturaleza femenina (en la que la vida intelectual siempre estaba menos presente). ${ }^{8}$ Como ha apuntado Elena Romiti, el espacio delimitado para las mujeres que escribían por entonces era el "de la lírica femenina intimista y amatoria”, ${ }^{9}$ cincelada con notas de juvenilismo y anti intelectualismo y representada por Delmira Agustini y Juana de Ibarbourou. ${ }^{10}$

Luisi no se amoldó a ninguno de estos mandatos y en ello debería buscarse, en gran medida, la impopularidad de sus poemas, en los que Mistral advertía "un repecho intelectual que el pueblo rehúsa hacer". ${ }^{11}$ Se dijo que su poesía era "cerebral”, "razonada”, "intelectual”, algo que no se esperaba de la lírica escrita por mujeres y que podría apuntarse como una de las afinidades de la autora con Sor Juana Inés de la Cruz ${ }^{12}$ (aunque ésta fue percibida por sus contemporáneos como una "especie de maravilla del Nuevo Mundo"). ${ }^{13}$ Si bien Vitale la valoró — con posterioridad— reconociéndola como la continuación de "la poesía filosófica y poco sensual de María Eugenia Vaz Ferreira”, ${ }^{14}$ en el Uruguay del Centenario, un juicio fue determinante para la recepción de su obra, el del iniciador de la crítica literaria nacional y principal patrocinante de obras del período, Alberto Zum Felde. Su Proceso intelectual del Uruguay e historia de la literatura (1930) determinó el canon nacional, al tiempo que la marginalidad de Luisi en él. La autora quedaba retratada de este modo:

Su poesía es todavía de cuño intelectualista, careciendo su floración gris, de aquella savia vital que viene de las oscuras raíces del ser, y —además, o ante todo— de aquel puro sentido estético, que da valor primario a toda cosa de arcerebralidad, la alianza de lo sensitivo y lo reflexivo. No es tanto el sensualismo vital lo que poetizan, sino una intensidad lúcida no exenta de pasión o de sentimiento. Escribe Luisa, a raíz de los versos de Sor Juana: "No llegan ellos naturalmente a los sensuales alardes que constituyen en nuestra época la más característica expresión de la poesía femenina, sobre todo de América, cuya cuerda única parece vibrar al estímulo único del erotismo” (Luisi, "Sor Juana Inés de la Cruz", p.155).

13

14

A primera vista, tanto la poética de Sor Juana como la de Luisa combinaron la pasión y la Franco, Las conspiradoras. La representación de la mujer en México, p. 52.

Vitale, Los poetas del Veinte, p. 331.

Cfr. Maristany "Maestras que escriben: entre el aula, el público y la academia”.

Romiti, Las poetas fundacionales del Cono Sur, p. 24.

Cfr. Torres, "Una poeta para América: hipótesis de lectura sobre la obra de Juana de Ibarbourou en la década de 1920".

Mistral, "Mensaje sobre Luisa Luisi”, s/p. 
te. Las más estimables composiciones de Luisa Luisi, son aquéllas más breves en que se ha olvidado de los problemas filosóficos y los conceptos de cátedra, para emitir voces de su propia intimidad vital. ${ }^{15}$

Esta condena, que le restó visibilidad en el sistema literario, la desanimó profundamente. Las escasas disidencias ante la opinión hegemónica fueron propuestas por otras mujeres, como la intelectual anarquista Lucce Fabbri. Al comentar Poemas de la inmovilidad, Fabbri señaló: "No comprendo cómo esta colección de versos profundamente sentidos se ha podido encontrar demasiado filosófica, demasiado teórica, demasiado razonada. ¿Cuándo la profundidad del pensamiento ha estado en oposición con la verdadera poesía?”. ${ }^{16}$ Sin duda lo que se le censuraba a Luisi no era su presencia en la "ciudad letrada" uruguaya — marcada tempranamente por la centralidad de la escritura femenina—, sino que rebasara el perímetro literario —el molde lírico- legitimado para las mujeres. En el mismo sentido debe inscribirse su labor como crítica literaria, un espacio que por entonces las mujeres hollaban tímidamente, en tanto su ejercicio demandaba una racionalidad de la que ellas seguían estando excluidas. Tampoco en éste la autora tuvo el reconocimiento que hubiera merecido; su quehacer interpretativo (sobre el que volveremos más adelante) fue desestimado por impresionista. Publicó estudios como La poesía de Enrique González Martínez (1923), A través de libros y autores (1925), La literatura uruguaya del Centenario (1930) y El teatro de García Lorca (1937), entre otros muchos comentarios críticos sueltos en revistas. ${ }^{17} \mathrm{Al}$ parecer, Luisi resultaba poco emocional para la poesía y demasiado expresiva — subjetiva— como crítica literaria.

Durante sus últimos años de vida, la incomprensión por parte del sistema literario nacional ${ }^{18}$ y la intensificación de enfermedades de índole nerviosa — que derivaron en una parálisis a mediados de los años veinte- sumieron a la escritora en el ostracismo. Las limitaciones de la enfermedad - que le provocaba profundos estados de fatiga y decaimiento- y la obediencia a indicaciones médicas, la llevaron a alternar su vida entre Montevideo y Santa Lucía, por entonces un pueblo alejado del ajetreo de la ciudad capital donde la

15 Zum Felde, Proceso intelectual del Uruguay y crítica de su literatura, p. 192.

16 Fabbri, “Luisa Luisi. Algunos de sus aspectos literarios comentados”, p. 22.

17 Su colega y amiga Gabriela Mistral, la equiparó a Zum Felde (en lo que consideramos fue un meditado acto de justicia): “[Luisi] pudo ser el biógrafo de la literatura uruguaya, junto al maestro Zum Felde y dar toda la anchura a su enorme capacidad de juzgar. Los textos literarios era para ella transparentes, como la paja en el hielo”. Mistral, "Mensaje sobre Luisa Luisi”, s/p.

18 “Soy una fracasada, amigo Reyes, y esta es la única razón de mi silencio”, Luisi. Carta del 25 de octubre de 1931. Archivo particular de Alfonso Reyes. Capilla Alfonsina/INBA. 
autora procuraba frenar el avance de su dolencia. ${ }^{19}$ El retiro de la vida mundana y la percepción de un cuerpo enclaustrado por la enfermedad recorren gran parte de su obra y podrían señalarse, salvando las distancias, como otro punto de afinidad con la trayectoria vital de la autora del Primero Sueño.

\section{LUISI Y SOR JUANA EN CONTEMPORÁNEOS}

¿Cómo llega Luisi, escritora distante de la estética de vanguardia y de la tendencia cosmopolita de los Contemporáneos (anclada aún en la estética modernista que la inclinaba hacia la poesía de Nervo y González Martínez), a las páginas de la revista fundada en 1928 por Torres Bodet, González Rojo, Ortiz de Montellano y Villaurrutia? El puente entre los jóvenes escritores que animaban la publicación y la intelectual uruguaya, antes que una afinidad generacional o estética, fue Alfonso Reyes, por entonces Embajador en Buenos Aires, y la diplomacia literaria del México posrevolucionario. ${ }^{20}$ En enero de 1928, el escritor comenzaba una relación epistolar con Luisi, quien presidía, desde la orilla oriental del Plata, un comité de solidaridad con México. ${ }^{21}$ En lo que siguió de ese año y de 1929, Luisi recurrió con frecuencia a Reyes para obtener ayuda en la organización de las actividades del Comité. El escritor le reconocía a la uruguaya "su eficaz y operante simpatía por

19 En cierto modo, habría que buscar en las vivencias a las que estuvieron expuestos sus cuerpos, puntualmente en el encierro del claustro o en la inmovilidad de la parálisis o la vida de reclusión en el hospital, la otra porción de motivos para la empatía crítica y humana (existencial) que manifestó la escritora uruguaya por Sor Juana. En Luisi, la experiencia de la enfermedad y del sanatorio se representa como la renuncia al mundo y a su propio cuerpo, y en cierto sentido como una femineidad incompleta, similar a la percepción del cuerpo de una monja en tanto representa la "renuncia a lo que en nuestra cultura son los atributos de una mujer como género: la sexualidad procreadora y la erótica” (Lagarde, Los cautiverios de las mujeres: Madresposas, monjas, putas, presas y locas, p. 548). En el libro Inquietud, en el poema titulado “Mi vida”, leemos: “Oh mi vida monjil en estancias soleadas / frente al cielo extendido y a la ciudad de hinojos / entre libros marchitos y rosas perfumadas” (Luisi, Inquietud, p. 106).

20 Las memorias del viaje a Montevideo de Salvador Novo en 1933 dan cuenta de los vínculos que los Contemporáneos “heredaron” de las misiones diplomáticas de Vasconcelos y de Reyes en el Río de la Plata durante los años veinte. Los escritores uruguayos con los que se relaciona Novo durante su estadía pertenecen a la red establecida por la generación anterior. Cfr. Novo, Continente vacío. Viaje a Sudamérica.

21 El organismo, conformado por más de cuarenta intelectuales uruguayos, buscaba apoyar, desde el frente cultural, al gobierno del presidente Calles. Deseosa de dotar de prestigio a su labor, la agrupación invitó a Reyes a visitar Montevideo para inaugurar un ciclo de actividades de propaganda cultural con un homenaje a México. El autor de Visión de Anáhuac aceptó el ofrecimiento y viajó a Uruguay a finales de mayo de 1928. Se trató de su primera visita oficial al país y una instancia sumamente valiosa para el acercamiento cultural entre ambas naciones. Cfr. Moraes, “Crónica de una efusión: Alfonso Reyes, Luisa Luisi y el Comité Uruguay-México”. 
México", ${ }^{22}$ todo un activo para la "buena” propaganda de su país en el Cono Sur. Precisamente, de esos empeños surgió la primera versión del estudio que luego sería enviado a Contemporáneos. En agosto de 1928, Luisi brindó en Montevideo una conferencia sobre Sor Juana Inés de la Cruz. Decidió enviarle el texto a Reyes con la intención de conocer su opinión al respecto, manifestarle su deseo de ampliar el trabajo y publicarlo en México. El diplomático respondió auxiliándola con los materiales necesarios para que completara su estudio; solicitó incluso que la Secretaría de Relaciones Exteriores de México, a través de Genaro Estrada, obsequiara a la autora una colección de publicaciones que la animaran a completar su ensayo:

La poetisa uruguaya Luisa Luisi ha leído recientemente una conferencia sobre Sor Juana de la Cruz, que ella quiere ampliar hasta hacer un verdadero libro. Le he hecho prescindir de la idea de incluir en la obra una antología de Sor Juana, porque eso ya lo ha hecho en México Touissant, y porque Emilio Abreu Gómez va a ser el editor filológico de Sor Juana. Luisa Luisi necesita que le envíen de México las obras de Pimentel (lo que haya de él o sobre Sor Juana), el México viejo, de González Obregón, y cuanto haya digno de consultarse sobre Sor Juana. ${ }^{23}$

Cuando el trabajo estuvo concluido, Reyes, cercano al comité editorial de Contemporáneos ${ }^{24}$ y comprometido con el objetivo de lograr colaboraciones en el Río de la Plata, gestionó su inclusión en la revista. ${ }^{25}$ Por ese entonces, cabe recordar, ésta recibía el patrocinio de la Secretaría de Relaciones Exteriores, a través de Genaro Estrada, factor que explica el interés de Reyes en lograr firmas extranjeras y la aparente facilidad con la que podía incidir en la publicación de ciertas colaboraciones.

Por otra parte, la integración del trabajo de Luisi en la revista refleja la concepción de la literatura y de la cultura promovida por Contemporáneos desde un cosmopolitismo universalista que, aunque pretendiera acercar las literaturas de Europa y Estados Unidos a México, se mantenía igualmente atento a la difusión de la literatura latinoamericana. Pero aún más, habría con el poder (como colaboradores de Vasconcelos en particular), lo que favoreció que fueran empleados en instituciones de educación superior o en el servicio exterior mexicano y tuvieran un acceso diferencial a escritores consagrados y editores. Según el crítico, esto también les permitió tener el monopolio de las secciones literarias de las publicaciones culturales. Sheridan, Los Contemporáneos ayer, p. 126.

25 Le indicó a Estrada que la monografía de Luisi "iría manuscrita a México en mi valija, para que allá se publique”. Reyes, Con leal franqueza, p. 163. 
que subrayar el hecho de que la colaboración de la uruguaya fue funcional, en cierto modo, a la idea de una cultura nacional defendida por el "grupo sin grupo" que eran los Contemporáneos, dado que su ensayo abordaba la figura de Sor Juana Inés de la Cruz, en torno a la cual aquellos habían emprendido una labor de rescate y revalorización. Esta cruzada —en realidad, la intensificación de la corriente de recuperación de la poeta novohispana emprendida en 1910 por Amado Nervo con el ensayo Juana de Asbaje - respondía a la búsqueda de los escritores de Contemporáneos de un modelo que les ayudara a promover uno de los principios más caros a su programa estético y que los distanciaba de la obstinación del arte nacionalista que llevaba adelante parte del sistema cultural posrevolucionario: el logro de una literatura moderna de exigencia universal. ${ }^{26}$

Hasta la mirada de Nervo, la obra de Sor Juana había dormido un largo sueño de casi dos siglos a raíz de los prejuicios literarios e ideológicos de los neoclásicos primero y de los románticos después hacia la estética barroca; para ellos, los escritos de la monja poeta se presentaba como un producto corrompido y ampuloso, resultado de la decadencia del gongorismo. Y fue precisamente con el aniversario del tercer centenario de la muerte de Góngora, en 1927, y la valorización del poeta en España y México, que afloró el entusiasmo sorjuanista y el consecuente rescate de su obra entre los Contemporáneos. Así, tenemos que en septiembre de 1928, Emilio Abreu Gómez publicó en Contemporáneos una edición del Primero sueño de Sor Juana y un par de años después, Villaurrutia una edición de los sonetos. También, cabe apuntar, manejaron un proyecto para editar las obras completas de la autora, que finalmente no se llevó a cabo. En ese contexto de producción y de recepción, se inscribía el ensayo de la crítica uruguaya, quien — como se verá en lo que sigue - vendría a proponer su propia versión del rescate de Sor Juana.

\section{SOR JUANA INÉS DE LA CRUZ PARA LA CRÍTICA LITERARIA FEMENINA}

Adentrarse en la valoración del ensayo de Luisi "Sor Juana Inés de la Cruz", exige observar brevemente al referente más decisivo para la recepción de la poeta novohispana entre las escritoras sudamericanas: Gabriela Mistral. El paso de la autora chilena por el México posrevolucionario (1922-1923), como agente de las políticas educativas de José Vasconcelos, favoreció la publicación del ensayo biográfico "Silueta de Sor Juana Inés de la Cruz",

${ }^{26}$ Cfr. Stanton, “Sor Juana entre los Contemporáneos”. 
incluido en la antología Lecturas para mujeres (1923). La mirada de Mistral sobre la eximia poeta criolla en los años veinte, momento en que las mujeres comenzaban a pisar con firmeza en el campo literario e intelectual, no resulta baladí. Todo lo contrario, expresa la necesidad de las escritoras latinoamericanas de forjarse una genealogía, esto es, de hallar una "madre literaria" que ayudase a cimentar su legitimidad en el ámbito de la cultura letrada. De este modo, Mistral construye a Sor Juana como modelo, subrayando como virtudes su sed por saber, su dedicación al estudio y su devoción cristiana. ${ }^{27}$

Por su parte, el ensayo de Luisa Luisi publicado en Contemporáneos se propone con base en un recorrido por la historia de las lecturas críticas construidas en torno a la obra de la autora y el reclamo de ésta para la crítica literaria escrita por mujeres. Cabe apuntar que precisamente en la década de 1920 se registra la aparición de los primeros trabajos de la crítica literaria femenina sobre la obra de Sor Juana. Sin ir más lejos, en el mismo número de Contemporáneos en el que figura el texto de Luisi, aparecía también un trabajo de la académica estadounidense Dorothy Schons, considerada la primera sorjuanista mujer. ${ }^{28}$

El texto de Luisi se organiza en tres partes. En la primera se encuentra una extensa disquisición acerca de la suerte de la obra de Sor Juana Inés de la Cruz a manos de la crítica literaria masculina; la segunda consiste en una relación de sus primeros años, mientras que la tercera se detiene sobre la cuestión de cuáles fueron los motivos que llevaron a Sor Juana a ingresar al convento jerónimo (un amor prohibido o la sed de conocimiento). Si bien es en este último estadio donde Luisi se bate con los críticos más reconocidos de la "Monja poeta" - defendiendo el temperamento apasionado de la escritora, más que sus habilidades conceptistas, a través del comentario de sus versos de amor-, en este trabajo nos interesa profundizar en la primera sección. Allí, la autora apunta:

Juana Inés ha esperado hasta ahora el alma comprensiva y semejante, de un soplo animador tan potente, que por encima de todo lo escrito sobre ella, y a través de sus poemas enmarañados o sencillos, sepa encontrarla verdadera-

27 La vitalidad de Sor Juana en el campo literario latinoamericano de esos años y la relevancia de esta estrategia de construcción de parentesco o de un linaje con una figura modélica se demuestra incluso en el acto de consagración de Juana de Ibarbourou, en 1929, cuando Alfonso Reyes ungió a la autora de Raíz salvaje como la "otra Juana de América”, evocando de este modo la figura tutelar de su compatriota. Cfr. Reyes, “Otra Juana de América”.

28 De hecho, varias décadas después, Octavio Paz, en la introducción a su estudio Sor Juana Inés de la Cruz o las trampas de la fe, revisaría tres siglos de bibliografía crítica sobre la poeta y apuntaría: "las últimas en llegar fueron las mujeres, pero han reparado el retraso con entusiasmo”. Paz, Sor Juana Inés de la Cruz o las trampas de la fe, p. 12. 
mente en la esencia misma de su realidad prístina, y la restituya viva y palpitante, a la inmortalidad definitiva. ${ }^{29}$

De la revisión y valoración de los aportes de los críticos varones (el padre Diego de Calleja, Castorena y Ursúa; Lorenzo González de la Sancha y Carlos Sigüenza y Góngora, Menéndez Pelayo; el Padre Feijóo, Luis Urbina, su admirado Amado Nervo), Luisi concluye:

En todas estas copiosas páginas, eruditas, sabias, abundantes, hiperbólicas muchas, he sentido palpitar a Sor Juana Inés, con el ansia atormentada por vivir en la plenitud no lograda de su verdad. Hombres que se acercaron a su alma, no pudieron obtener de ella sino la fría apariencia que la desgraciada época literaria en que la suerte la arrojó a la vida... ${ }^{30}$

La nota singular del planteo de la escritora uruguaya radica en la construcción de Sor Juana como una autora encarcelada en la crítica literaria masculina, “estrechamente aprisionada en tan angosta y oscura cárcel”. ${ }^{31}$

Acaso tan sólo un alma de mujer, apasionada y vehemente como la suya, pueda acercarse a ella con suficiente calor de afecto y afinidad de comprensión que no tuvieron sus biógrafos masculinos. (...) No se tomen sin embargo mis palabras como la presuntuosa afirmación de una verdad comprobada. Otras veces, frecuentes, he sostenido mi personal interpretación de la crítica que algunos han dado en llamar impresionista. ${ }^{32}$

Como puede verse, la estrategia de Luisi consiste en separarse del pretendido empirismo del crítico varón de su tiempo dotando de valor al componente personal en la lectura crítica:

Yo sólo intento dar de mi poetisa la visión personalísima que he recogido de la lectura de sus obras en primer término, de la lectura de sus biógrafos, después. Acaso esta imagen que intento bosquejar de la Monja poeta, no sea sino un producto exclusivo de mi fantasía; pero acaso también haya en ella mucha más realidad que en los datos escuetos de la historia literaria. ${ }^{33}$ 
Resulta difícil no reparar en este gesto diferenciador de su ejercicio críticohermenéutico como un intento de subvertir la autoridad masculina que, como se ha venido planteando, ordenaba su quehacer intelectual, definía el canon literario y estipulaba cómo se hacía crítica literaria en su tiempo. Luisi reivindica en "Sor Juana Inés de la Cruz" otra "razón" crítica, de forma similar a como procedió la propia poeta novohispana ante sus impugnadores, esto es, defendiendo otras formas de discurso racional, distintas de las legitimadas por el relato hegemónico del patriarcado. ${ }^{34}$ Como Oscar Wilde en el ensayo The Critic as Artist, la uruguaya borra el límite entre el arte y la crítica, proponiendo que esta última debería consistir en un desarrollo creativo más, que "tiene algo de alumbramiento divino, en este libertar de almas, ayudándolas a destacarse hacia la luz; algo de creación celeste al dar cuerpo espiritual a las sombras que luchan desesperadamente en los limbos inciertos de su producción literaria”. ${ }^{35}$

Algunas afirmaciones de Luisi acerca del quehacer del crítico, escritas con anterioridad a este ensayo publicado en Contemporáneos, evidencian una verdadera preocupación y un proceso en la autora respecto de este asunto. Así, en el prólogo de A través de libros y autores (1925), intentó diferenciar los trabajos allí reunidos de la categoría de "crítica literaria": "He huido expresamente el calificarlos con el presuntuoso nombre de 'críticas', por cuanto el significado que generalmente se asigna a tal palabra está lejos de traducir el estado de mi alma. Yo no creo en la función directiva que se arroga con tal presunción la llamada crítica literaria”. ${ }^{36}$ Antes bien, la autora presenta sus trabajos como "una opinión personal" o como la traducción de sus sentimientos ante los libros. De esta forma, Luisi declara que no "lee" como el varón, en el sentido de que no "explica" de forma objetiva y razonada, como se espera del ejercicio de la "crítica literaria"; antes bien, llega a la verdad del texto creando, fantaseando. Se podría ver en este recurso una suerte de "treta del débil" como denominó Josefina Ludmer a la estrategia oblicua, desarrollada por Sor Juana en la Respuesta a sor Filotea de la Cruz para resistir a su subalternidad en relación a la hegemonía patriarcal. ${ }^{37}$ De modo similar a la autora de Los empeños de una casa, Luisi interviene en el debate sobre la crítica literaria, pero negándose a sí misma la categoría de “crítica literaria”, esto es, callando (o mejor, callándose algo). Asumir abiertamente el papel de lectora especializada hubiera significado transgredir un límite o ingresar a un espacio de poder que por entonces seguía estando 
vedado a las mujeres. ${ }^{38}$ Como Sor Juana, quien, desobedeciendo a San Pablo y a sus confesores, quiso interpretar las Sagradas Escrituras y escribir sobre teología, toda una "intromisión en el púlpito", ${ }^{39}$ el texto de Luisi defiende la libertad de las mujeres para desarrollar un género percibido como masculino: la crítica literaria.

En el fondo de la propuesta de Luisi se encuentra no tanto un reclamo justiciero y solidario con su género de Sor Juana para la crítica literaria femenina, sino, como ha estudiado Jean Franco, la lucha de la mujer por el poder de interpretar. ${ }^{40}$ Visto de este modo, el camino de la conquista femenina de las competencias vinculadas a la escritura y el pensamiento (la reflexión científica y filosófica, la academia, etcétera) guardaría cierta continuidad desde la autora novohispana hasta Luisa Luisi. Esta última, aunque ya liberada de la sumisión a un clero religioso y una teología antropocéntrica, debió experimentar las limitaciones impuestas por ese clero laico en el que se constituyeron los intelectuales varones en América Latina, heredando la labor de censores (y patrocinadores) de los discursos. En síntesis, las tensiones que experimentaba Luisi en el campo literario uruguayo, un circuito abierto a la intervención femenina, pero siempre que estuviera mediada por el varón a través de acciones vinculadas con el patrocinio, la promoción o la exclusión se ven doblemente representadas en este texto. Por un lado, en la propia elección e identificación de sí misma con una autora que fue censurada por el orden patriarcal (a través de sus superiores eclesiásticos) y por otro, en su reclamo de Sor Juana para un modo de leer diferente, la lectura crítica de corte impresionista, que Luisi asocia al género femenino.

\section{CONCLUSIONES}

En su paso por Uruguay en 1922, José Vasconcelos constataba en el país la falta de interés por lo latinoamericano. Describía una intelectualidad afrancesada, desligada de América, adherida a cierto "nacionalismo" o regionalismo que "no está de acuerdo con el aliento continental de Rodó". ${ }^{41}$ A contrapelo de esto, la publicación del ensayo de Luisi en Contemporáneos, en 1929, refleja el acercamiento de la intelectualidad uruguaya a la cultura

38 La misma estrategia aparece en The Common Reader, de Virginia Woolf, cuya primera serie fue publicada en 1925. En el que el lector común con el que se identifica Woolf es distinto del crítico o del académico. Desconocemos si Luisi tuvo entre sus lecturas esta obra de la escritora inglesa.

Franco, Las conspiradoras, p. 71.

Ibíd., p. 11.

Vasconcelos, La raza cósmica. Notas de viaje, p. 148. 
mexicana y la renovación de las redes del americanismo, aspectos que deben reconocerse como logros de la diplomacia de las letras del México posrevolucionario.

Por otra parte, la inclusión del ensayo "Sor Juana Inés de la Cruz" en Contemporáneos, escrito por una autora que no se destacaba como especialista en la obra de la poeta novohispana, debe interpretarse en relación a la promoción, que llevaban adelante los escritores reunidos en torno a la revista, de Sor Juana como modelo de una literatura nacional de alcance y calidad universal en el marco del debate acerca de la cultura posrevolucionaria.

La singularidad del trabajo de Luisi en el marco de la recuperación de la obra de Sor Juana desarrollada por Contemporáneos radica en su propuesta de rescatar a la autora para la crítica literaria femenina. La elaboración de Luisi resulta simbólicamente potente puesto que mostraría una continuidad en el encierro de Sor Juana (en el convento y en el silencio, cuando renuncia a la escritura profana a causa de las presiones eclesiales) al presentarla retenida en las interpretaciones masculinas de su obra. El texto, según se ha podido ver, posee el valor de una declaración o reivindicación del lugar de las mujeres en el ejercicio de la interpretación, aspecto que hemos propuesto debe comprenderse a la luz de la propia trayectoria de Luisi. La identificación con Sor Juana en el texto, la propia escritura del ensayo y su publicación en una revista mexicana fueron seguramente para la autora una forma de subsanar, aunque más no fuera simbólicamente, su falta de legitimidad como crítica y como poeta en el campo literario uruguayo.

\section{REFERENCIAS BIBLIOGRÁFICAS}

\section{Archivo}

Archivo Particular de Alfonso Reyes. Capilla Alfonsina/ INBA/ Secretaría de Cultura, México, Expediente $n^{\circ} 1498$, Luisa Luisi.

\section{Bibliografía}

Achugar, Hugo, "La década del veinte. Vanguardia y batllismo. El intelectual y el Estado", en Autores varios, Vida y Cultura en el Río de la Plata, Montevideo, Universidad de la República, Departamento de Publicaciones, 1987, pp. 99-116.

Fabbri, Luce, "Luisa Luisi. Algunos de sus aspectos literarios comentados”, La pluma 17, Montevideo, 1931, pp. 21-25.

Franco, Jean. Las conspiradoras. La representación de la mujer en México, Mercedes Córdoba (trad.), México, FCE/COLMEX, 2004. 
Lagarde, Marcela, Los cautiverios de las mujeres: Madresposas, monjas, putas, presas y locas, Ciudad de México, Siglo XXI Editores, 2005.

López, Sara, El legado de las hermanas Luisi, cien años después, Montevideo, Universidad de la República, 2013.

Ludmer, Josefina, “Tretas del débil”, en González, Patricia Elena y Eliana Ortega (eds.), La sartén por el mango. Encuentro de escritoras latinoamericanas, Puerto Rico, Ed. El Huracán, 1984, pp. 47-54.

Luisi, Luisa, Inquietud, Montevideo, Ed. Pegaso, 1921.

—, A través de libros y autores, Buenos Aires, Ediciones de Nuestra América, 1925.

__, “Sor Juana Inés de la Cruz”, Contemporáneos 9 (febrero 1929), en Revistas literarias mexicanas modernas. Contemporáneos III, enero-marzo de 1929 IV, abril-julio de 1929, edición facsimilar, México, FCE, 1981, pp. 130-160.

Maristany, José J., “Maestras que escriben: entre el aula, el público y la academia”, La Aljaba 3 (1998). 177-197.

Mistral, Gabriela, “Silueta de Sor Juana Inés de la Cruz”, en Lecturas para mujeres México, Secretaría de Educación de México, 1924, pp. 130-135.

—_, "Mensaje sobre Luisa Luisi”, Mundo Uruguayo 411, 24 de noviembre de 1940, s/p.

Moraes Medina, Mariana, “Crónica de una efusión: Alfonso Reyes, Luisa Luisi y el Comité Uruguay-México”. Revista de Historia de América, núm. 156, 2019, 217-239.

Novo, Salvador. Continente vacío. Viaje a Sudamérica, en Viajes y ensayos I. Sergio González Rodríguez (comp.), México, Fondo de Cultura Económica, 1996.

Paz, Octavio, Sor Juana Inés de la Cruz o Las trampas de la fe, México, Seix Barral, 1993.

Reyes, Alfonso, “Otra Juana de América” [1929], en Grito de auxilio. Correspondencia. Serge I. Zaïtzeff (comp.), Ciudad de México, El Colegio Nacional, 2001.

Reyes, Alfonso y Genaro Estrada, Con leal franqueza. Correspondencia entre Alfonso Reyes y Genaro Estrada. Tomo II. Compilación y notas de Serge I. Zaïtzeff, México, El Colegio Nacional, 1993.

Romiti, Elena, Las poetas fundacionales del Cono Sur: aportes teóricos a la literatura latinoamericana, Montevideo, Biblioteca Nacional de Uruguay, 2013.

Salaverri, Vicente, “Presencia de Luisa Luisi”, Revista Nacional, núm. 182 (febrero 1954), 229-231.

Sheridan, Guillermo, Los Contemporáneos ayer, México, Fondo de Cultura Económica, 1985.

Stanton, Anthony, "Sor Juana entre los Contemporáneos”. Crítica sin fin: José Gorostiza y sus críticos, ed. Álvaro Ruíz Abreu, México D.F., Conaculta, 2003, pp. 279-307. 
Torres, Inés de, “Una poeta para América: hipótesis de lectura sobre la obra de Juana de Ibarbourou en la década de 1920”, Cuadernos de literatura 34, juliodiciembre, 2013, pp. 202-216.

Vasconcelos, José, La raza cósmica. Notas de viaje, España, Espasa Calpe, 1925.

Vitale, Ida, Los poetas del Veinte, en Capítulo Oriental. Historia de la Literatura Uruguaya, núm. 21, Buenos Aires, Centro Editor de América Latina, 1971.

Woolf, Virginia, The common reader, London: Mariner Books, 1984.

Zum Felde, Alberto, Proceso intelectual del Uruguay y crítica de su literatura, tomo III, Montevideo, Imprenta Nacional Colorada, 1930. 